\title{
Prevalence of lameness and leg lesions of lactating dairy cows housed in southern Brazil: Effects of housing systems
}

\author{
Joao H. C. Costa,${ }^{*}{ }^{1}$ Tracy A. Burnett, $\dagger$ Marina A. G. von Keyserlingk, $\dagger$ and Maria J. Hötzel ${ }^{* 2}$ \\ *Laboratório de Etologia Aplicada e Bem-Estar Animal (LETA), Departamento de Zootecnia e Desenvolvimento Rural, \\ Universidade Federal de Santa Catarina, Rod. Admar Gonzaga, 1346, Itacorubi, 88034-001, Florianópolis, SC, Brazil \\ †Animal Welfare Program, University of British Columbia, 2357 Mall, Vancouver, BC, Canada, V6T 1 Z4
}

\section{ABSTRACT}

Within the last few decades, the North American and European dairy industries have been collecting information about lameness and leg injury prevalence on dairy farms and have tried to develop solutions to mitigate these ailments. Few published articles report the prevalence of lameness and leg lesions in areas outside of those 2 regions, or how alternative housing systems, such as compost-bedded packs, affect the prevalence of these maladies. The objectives of this study were to compare the prevalence of lameness and leg lesions on confined dairies that used freestall, compost-bedded packs, or a combination of these 2 systems in Brazil. Data were collected in the autumn and winter of 2016 from 50 dairy farms located in Paraná state, including 12 compost-bedded pack dairies (CB), 23 freestall dairies (FS), and 15 freestall dairies that used compostbedded packs for vulnerable cows $(\mathrm{FS}+\mathrm{C})$. A visit to the farm consisted of a management questionnaire, an inspection of the housing areas as well as the milking parlor, and an evaluation of all lactating cows as they exited the parlor for lameness (score 1-5), hygiene (score 0-2), body condition score (score 1-5), and hock and knee lesions (score 0-1). Median 1-way chi-squared test was used to compare production systems. We found no difference between farm types in management practices related to hoof health management or average daily milk production per cow [31 (29-33.9) kg/d; median (quartile 1-3)], percentage of Holstein cattle in the herd $[100 \%(90-100 \%)]$, conception rate $[35.8 \%$ $(30.2-38 \%)]$, or pregnancy rate $[15 \%(13.7-18 \%)]$. The CB farms were smaller [85 (49.5-146.5) milking cows] than both the FS [270 (178-327.5) milking cows] and $\mathrm{FS}+\mathrm{C}$ farms $[360(150-541.5)$ milking cows $)$. The over-

\footnotetext{
Received July 8, 2017.

Accepted October 26, 2017.

${ }^{1}$ Current address: Dairy Science Program, Department of Animal and Food Sciences, University of Kentucky, 325 Cooper Dr., Lexington 40546.

${ }^{2}$ Corresponding author: maria.j.hotzel@ufsc.br
}

all prevalence of severe lameness (score 4 and 5 ) across all farms was $21.2 \%(15.2-28.5 \%)$ but was lower on the CB farms $[14.2 \%(8.45-15.5 \%)]$ in comparison to the FS $[22.2 \%(16.8-26.7 \%)]$ and the FS+C farms $[22.2 \%$ (17.4-32.8\%)]. Less than $1 \%$ of all cows scored on CB farms were observed with swollen or wounded knees (or both), which was lower than either the FS or FS+C farms $[7.4 \%(3.6-11.9 \%)$ and $6.4 \%(2.6-11.8 \%)$ of all cows scored, respectively]. The same pattern was found for hock lesions, where the farm-level prevalence within the 3 different housing types was $0.5 \%(0-0.9 \%), 9.9 \%$ $(0.8-15.3 \%)$, and $5.7 \%(2.6-10.9 \%)$ for $\mathrm{CB}$, FS, and FS +C farms, respectively. No differences between farm systems were observed for hygiene or body condition score. On average, $2.7 \%(0.8-10.9 \%)$ of lactating cows had a soiled side, $15.4 \%(2.1-37.4 \%)$ had dirty legs and $1.7 \%(0-9.3 \%)$ had dirty udders. The average herd-level body condition score across farms was 2.9 (2.9-3), with $0.86 \%$ of the all cows scored having a body condition score $<2.5$. These results indicate that lameness prevalence on confined dairies in Brazil is high and highlight the need for remedial changes in environmental design and management practices. We found that $\mathrm{CB}$ farms in this region had reduced lameness and lesions in relation to $\mathrm{FS}$ or $\mathrm{FS}+\mathrm{C}$ dairies.

Key words: animal welfare, dairy cow, hock lesion, swollen knee, compost-bedded pack

\section{INTRODUCTION}

Lameness is a major animal welfare and productive challenge facing the dairy industry because it causes pain (O'Callaghan et al., 2003; Whay et al., 2003; Rushen et al., 2008; Potterton et al., 2012), reduces DMI and milk yield (Bach et al., 2007; Leach et al., 2012), and increases the risk of a cow being culled before the end of lactation (Bicalho et al., 2007). Many studies have investigated the prevalence of lameness on dairy farms across the globe, but these studies have focused on the most common confined housing systems, such as freestall and tiestall barns (Andreasen and Forkman, 
2012; von Keyserlingk et al., 2012; Metz et al., 2015; Solano et al., 2015; Westin et al., 2016; Adams et al., 2017; Bouffard et al., 2017). Little information is available on the prevalence of lameness and leg lesions on commercial farms within Brazil, or globally on dairies that use a mixture of freestall and compost-bedded packs.

Causes of lameness and leg lesions on dairy farms range from those related to the individual cow to environmental factors, and depending on particular conditions, the effect of each factor may vary (Cook and Nordlund, 2009; Chapinal et al., 2013, 2014). Due to the high prevalence of hoof problems and leg lesions found in cows housed within freestall housing across the globe (see review by Kester et al., 2014; Palmer and O'Connell, 2015), efforts have focused on identifying alternative housing and management strategies. For instance, deep-bedded stalls, improved stall maintenance, and access to pasture have all been associated with reduced lameness and hock lesions (Fulwider et al., 2007; Chapinal et al., 2013).

Compost-bedded packs consist of a large bedded area with a compostable material such as straw or sawdust that is typically aerated once or twice a day to facilitate the composting process and to mix the animals' waste with the compostable material (Janni et al., 2007). This system has gained traction in the United States (Black et al., 2013; Eckelkamp et al., 2016a,b) and in Europe (Klaas et al., 2010; Klaas and Bjerg, 2011), and is growing rapidly in Brazil. Compost-bedded packs enable animals to engage in more natural lying behaviors and permits more social interaction in comparison with the freestall housing systems (Endres and Barberg, 2007). Housing of dairy cattle on compost-bedded packs has been shown to improve health and longevity of the cow and, consequently, the productive performance of the animal (Norring et al., 2008; Fjeldaas et al., 2011; Lobeck et al., 2011). The work done to date on compostbedded packs collectively reports benefits, such as lower prevalence of claudication and hock and knee lesions in comparison with freestall systems (Barberg et al., 2007; Fulwider et al., 2007) and increases in hoof health of dairy cows (Klaas and Bjerg, 2011; Black et al., 2013).

Recently, some freestall farms have incorporated compost-bedded pack barns as special needs housing for their vulnerable animals (Eckelkamp et al., 2016a). This management practice is based on the notion that improved comfort for vulnerable cows would lead to improved leg and overall health of dairy cows but to date no work has investigated this management practice. Providing access to a more open housing system that has less structural hardware known to impede movements associated with lying (Ceballos et al., 2004) and has less concrete flooring, such as a compost-bedded packs, may help meet the behavioral needs and other necessities of special needs animals, such as transition cows (Eckelkamp et al., 2016a,b). It has been suggested that providing a soft area where cows have ample space to lie down is an important factor that may affect the health of transition cows (Cook and Nordlund, 2004), as both environmental and physiological factors that negatively affect the cow have been shown to suppress the immune system (Chebel et al., 2016). A recent US survey provides some indirect evidence that the strategy of using compost-bedded packs for vulnerable cows will decrease bulk tank SCC (Eckelkamp et al., 2016a).

In Brazil a growing number of dairy farms temporarily house their transition cows (and sick and lame cows) on compost-bedded packs before moving them back to freestall housing. Little is known regarding the use of this blended type of housing system on the prevalence of lameness and hock and knee lesions. Thus, the objectives of this study were to compare the prevalence of lameness and hock and knee lesions on confined dairies that used freestalls, compost-bedded packs, or a combination of these 2 systems in southern Brazil.

\section{MATERIALS AND METHODS}

A convenience sample of 50 confined dairy farms distributed in 4 municipalities in the central region of the state of Paraná was used in this study. This region is one of the most important milk production clusters in Brazil with a total milk production of more than 400 million liters from 70 thousand cows on 2,200 dairy farms (IPARDES, 2009). Farms were identified through extension agents, veterinarians and other dairy industry experts working in the Castrolanda Farmers' Cooperative (Castro, PR, Brazil). Some farms were recruited using a snowball technique, whereby farmers that had agreed to participate were asked to recommend other farmers that they believed would be willing to participate. Farmers were contacted directly by a member of the research team by telephone at which time, if the farmer was in agreement, an appointment for a visit was made. Of all farmers approached, only 2 declined to participate. This sampling regimen resulted in 3 groups of farms: 12 compost-bedded pack farms (CB), 23 freestall dairies (FS), and 15 freestall dairies with compost-bedded packs $(\mathbf{F S}+\mathbf{C})$ for vulnerable cows (such as transition and sick cows).

The study was carried out between March and October 2016. All procedures were approved by the Ethics Committees on Research on Humans (protocol \#PP1237779, 2015) and Animals of the Universidade Federal de Santa Catarina (protocol \#PP00949, 2014) and by the University of British Columbia Animal Care Committee (protocol \#A15-0082). 
Each farm was visited once. All animal- and facilitybased measures were performed by the same trained observer on all farms. The on-farm assessment protocol was adapted from von Keyserlingk et al. (2012) and Costa et al. (2013). Briefly, before the visit, the farmers were informed of the purpose of the study and were assured that their participation was voluntary and would be kept confidential. Once consent was obtained, the on-farm assessment took approximately 8 to $12 \mathrm{~h}$ depending on the size of the farm, and included an hourlong interview where we asked about the general management practices of the farm (i.e., how many times a day were cows fed, frequency of preventative hoof care, use of heat abatement, and so on), direct observation of the milking environment, milking routine, and the dairy cows. Whenever available, production and health records were gathered from the farmer and the dairy milk quality control agency (Programa de Análise de Rebanhos Leiteiros do Paraná/Associação Paranaense de Criadores de Bovinos da Raça Holandesa, Curitiba, PR, Brazil).

\section{Survey of Farm Practices}

Face-to-face interviews with the herd manager or owner (or both) were carried out using a questionnaire with multiple-choice and semi-closed questions to collect information regarding technical assistance, management and husbandry practices. The first section of the interview covered demographic data, such as the interviewee's age, education level, and number of years working in the dairy industry. Also, farm characteristics were collected, such as number of employees, number of dairy cattle in each category (calves, heifers, and cows), and total milk production. In addition, questions were asked regarding frequency and type of extension and veterinary services received and if lactating cows had access to pasture at any point of the year. At all times farmers had the opportunity to clarify questions and add personal information and remarks and withhold information if they so wished.

\section{Inspection of the Environment}

Inspection of the environment included the identification of the flooring type of the walkway to the parlor, the inclination of the walkway, total feed bunk space, number of waterers per pen, and linear water trough space per cow and stocking density. Total feed bunk space per cow was determined by measuring the available feeding space from the cows' perspectives and then dividing by the total number of cows within the pen. Total water trough(s) length from all accessible sides was measured and divided by the total number of cows within the pen to determine the linear water space $(\mathrm{cm})$ per cow. Number of cows per water trough was also calculated per group, dividing the number of cows present in the pen by the number of water troughs present; farm averages were then calculated weighted by the number of cows per group. Stocking density was calculated on a per-group basis and averaged for the farm. We considered the required space of $11 \mathrm{~m}^{2}$ per cow in the compost-bedded packs and 1 stall per cow in the freestalls as the $100 \%$ stocking rate and any ratio relative to that (DFC-NFACC, 2009).

\section{Inspection of the Animals}

The entire lactating herd, including hospital and special needs pens, was evaluated at each farm visited. The time of the visit was in relation to the farms' milking schedule, and cows were separated by pen. All lactating cows on each of the 50 farms were scored by a single, trained person, for lameness, hock and knee lesions, BCS, and hygiene as they exited the milking parlor. To determine lameness, we used the 5-point numerical rating system (NRS) scoring system proposed by Flower and Weary (2006), where $1=$ sound and $5=$ severely lame. For our analysis we categorized lameness either as clinical lameness (NRS $\geq 3$ ) or severe lameness (NRS $\geq 4$ ). The percentages of cows that were clinically and severely lame per herd were calculated.

Cows were inspected for leg lesions following the Hock Assessment Chart for Cattle developed by the Cornell Cooperative Extension (https://ecommons.cornell.edu/ bitstream/handle/1813/36913/hockscore.pdf?sequence $=1$ ), with some modifications: one limb per cow was scored at the area around the tarsal (hocks) and carpal (knee) joints on a 3 -point scale, where $1=$ healthy, 2 $=$ mild swelling and/or balding, and $3=$ swollen or an open wound, or both. Two measures of leg lesions were calculated: injury (score $\geq 2$ ) and severe injury (scores $=3$ ). Hock and knee lesion prevalence was calculated by determining the percentage of cows that presented the respective lesion type per herd (\%).

To evaluate BCS, animals were scored on a 5-point scale ranging from 1, indicating thin, to 5, indicating obese (Edmonson et al., 1989). Because only extreme BCS (too thin or too fat) are likely to cause negative effects on animal welfare (Roche et al., 2009), cows were classified as BCS $<2.5,=$ thin, $\mathrm{BCS} \geq 2.5$ and $\leq 4.0=$ ideal, and BCS $\geq 4.5=$ obese; the percentages of thin and obese cows per herd were calculated.

Hygiene scores used in this study followed Lombard et al. (2010). Each cow was scored on the udder, leg, and flank. The scoring system used was a 3-point scale where cows with no manure or dirt on the body part were assigned a score of 1 ; cows with small amounts of 
manure or dirt on the body part were assigned a score of 2 ; and cows soiled with large amounts of manure or dirt on the body part were assigned a score of 3 .

\section{Data Analyses}

Farm was considered as the experimental unit in all analyses. Prevalence for each condition was calculated separately for each farm. Frequencies of farms were calculated for categorical (binary and nominal) variables generated using PROC FREQ in SAS 9.4 software (Cary, NC). Descriptive statistics [median, quartile 1 (Q1), quartile 3 (Q3), means, standard deviation, range, minimum, and maximum] were calculated separately for each production system. Significance between management practices and categorical variables within the production systems were tested using chi-squared or Fisher's exact test when fewer than 5 observations were found in a cell. Descriptive statistics were calculated for continuous and ordinal variables using PROC NPAR1WAY, where medians, Q1, and Q3 were calculated. The median one-way chi-squared test was used to compare the 3 production systems for these variables. When the 3 -way analysis between housing systems was found to be a tendency $0.5<P<0.10$ or significant $(P$ $<0.05$ ), post hoc 2 -way comparisons between systems were carried out to determine where the difference lied and $P$-values were adjusted using the Bonferroni correction. The $P$-values presented in the results are from the 3 -way tests unless specified.

\section{RESULTS}

\section{Herd Characteristics, Environmental Assessment, and Management Variables}

The FS+C had 16\% (8.3-26.7\%; median Q1-Q3) of the milking cows housed on a compost-bedded pack. In addition, the FS $+\mathrm{C}$ farms housed all cows with the lowest DIM and those on medical treatments on the compost-bedded pack. Additionally, $73 \%$ of the FS+C farms also housed the cows that they identified as severely lame on the compost-bedded pack.

The FS and FS $+\mathrm{C}$ farms were larger in land area that was dedicated for milk production, had more cows and employees working on the farm, and had a greater total milk production than CB farms (Table 1). However, when variables were calculated on a per-cow basis farm characteristics were not different for the variables analyzed. Descriptive variables and herd data of each farm system are summarized in Table 1.

In total, $30 \%$ of farms had inclined walkways to the parlor and $98 \%$ of the walkways were made of grooved concrete (Table 2); neither of these variables differed

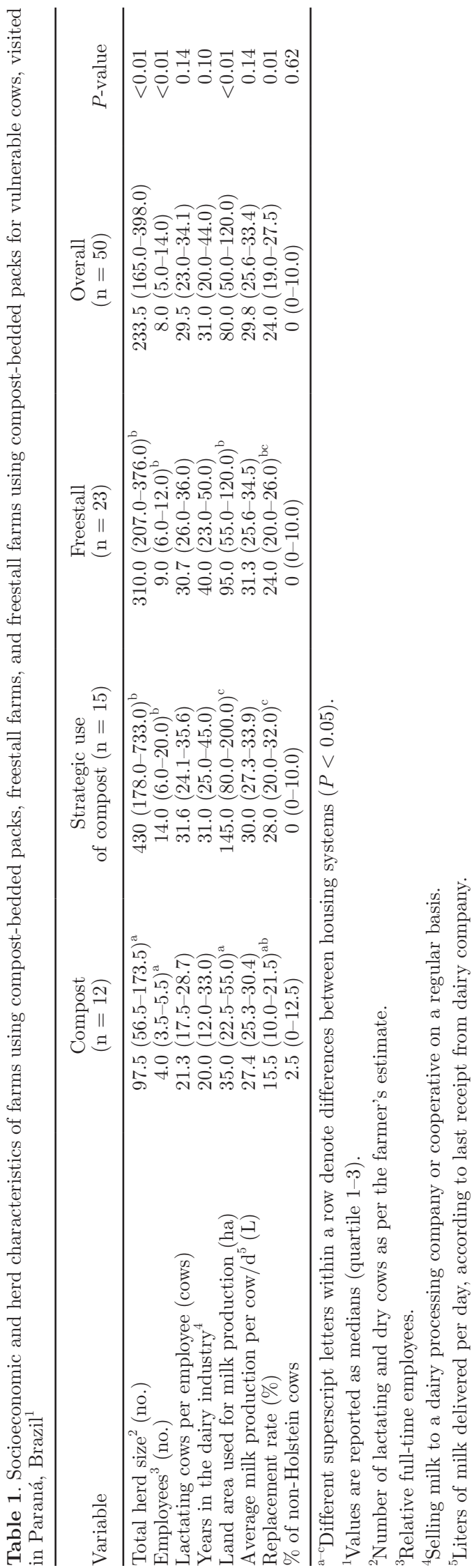

Journal of Dairy Science Vol. 101 No. 3, 2018 
among housing systems. Feed bunk space per cow, water availability, water trough space per cow, water source, the number of cows per waterer, and the presence of overstocking did not differ among housing systems (Table 2). No difference in bedding type was found between $\mathrm{FS}$ and $\mathrm{FS}+\mathrm{C}$ farms $(P=0.83)$. The FS farms used straw (4\%), sand (30\%), or sawdust (61\%), and $4 \%$ did not use bedding; FS+C farms bedded their stalls with straw $(7 \%)$, sand $(13 \%)$, or sawdust $(60 \%)$, and $20 \%$ used more than one bedding type. As expected, $100 \%$ of the CB farms were bedded with compost.

Use of heat abatement strategies also did not differ between housing systems, overall only $72 \%$ of the farms used at least one type of heat abatement system. No difference was observed between farm types in hoof health management practices or average daily milk production/cow per $\mathrm{d}$. The herds' predominant breed was Holstein and all farms raised their own replacement animals on site. Management variables are described in Table 3.

\section{Animal-Based Measures}

The overall prevalence of clinical lameness (score $\geq 3$ ) across all farms was $42.5 \%(34.0-48.0 \%)$ [median (Q1-Q3); Figure 1a], but was lower on the farms using only CB $[31.9 \%(27.5-35.5 \%)]$ in comparison with FS $[43.2 \%(35.4-48.6 \%)]$ and the FS+C farms $[45.4 \%$ (40.9-52.9\%); $P<0.01]$. The overall prevalence of severe lameness across all farms (score $\geq 4$ ) was $21.2 \%$ (15.2-28.5\%). Dairies using only CB also had a lower prevalence of severe lameness $[14.2 \%(8.45-15.5 \%)]$ in comparison with FS $[22.2 \%(16.8-26.7 \%)]$, and FS+C farms $[22.2 \%(17.4-32.8 \%) ; P=0.03$; Figure 1b].

Hock and knee lesion prevalence is presented in Figure 2. Less than $1 \%$ of all cows scored on the CB farms were observed with swollen or wounded knees (or both), which was lower than either the FS or FS+C farms $[7.4 \%(3.6-11.9 \%)$ and $6.4 \%(2.6-11.8 \%)$ of all cows scored, respectively; $P<0.01]$. Similarly, the farm-level prevalence of hock lesions was $0.5 \%(0-0.9 \%), 9.9 \%$ $(0.8-15.3 \%)$, and $5.7 \%(2.6-10.9 \%)$ on $\mathrm{CB}$, FS, and FS + C farms, respectively $(P<0.01)$.

Farm types did not differ for BCS or hygiene score (Table 4). On average, $2.7 \%(0.8-10.9 \%)$ of lactating cows had a soiled side, $15.4 \%(2.1-37.4 \%)$ had dirty legs, and $1.7 \%(0-9.3 \%)$ had dirty udders. The average herd-level BCS across farms was 2.9 (2.9-3), with $0.86 \%$ of the cows having a BCS $<2.5$.

\section{DISCUSSION}

Overall, the prevalence of clinical and severe lameness and leg lesions on all farms visited in this study was

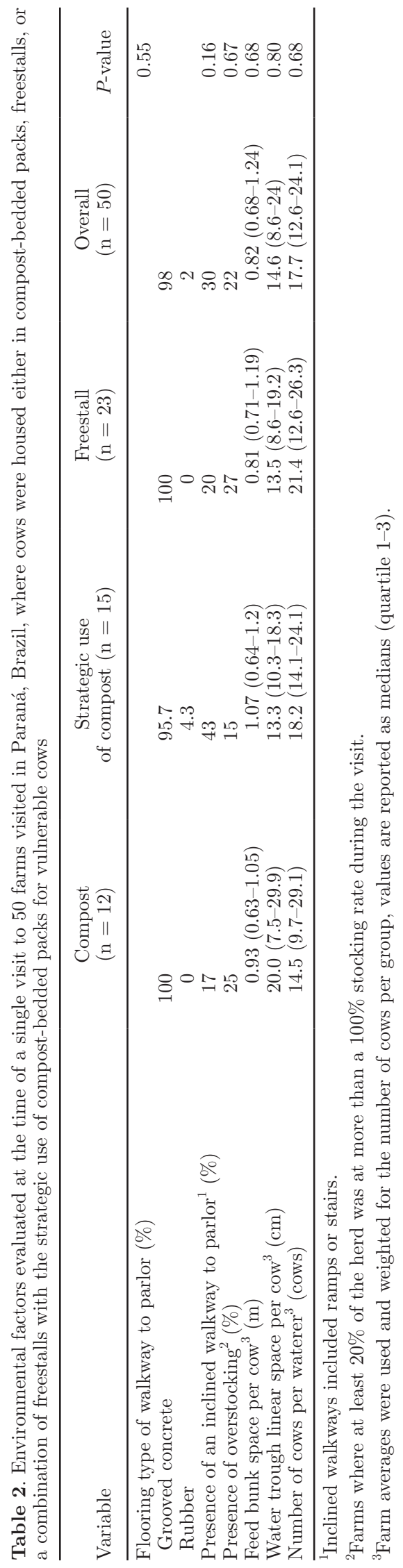

Journal of Dairy Science Vol. 101 No. 3, 2018 
Table 3. Management practices reported by producers owning compost-bedded packs, freestall farms, and freestalls with compost-bedded packs for vulnerable cows in Paraná, Brazil

\begin{tabular}{|c|c|c|c|c|c|}
\hline Management practice (\%) & $\begin{array}{l}\text { Compost } \\
(\mathrm{n}=12)\end{array}$ & $\begin{array}{c}\text { Strategic use } \\
\text { of compost }(\mathrm{n}=15)\end{array}$ & $\begin{array}{l}\text { Freestall } \\
(\mathrm{n}=23)\end{array}$ & $\begin{array}{l}\text { Overall } \\
(\mathrm{n}=50)\end{array}$ & $P$-value \\
\hline Footbath use & & & & & 0.14 \\
\hline Frequency of preventative hoof trimming per lactation & & & & & 0.64 \\
\hline Only problematic cows & 25 & 13 & 13 & 16 & \\
\hline Once & 8 & 13 & 26 & 18 & \\
\hline Use of a heat abatement system (fans, sprinklers, or both) & & & & & 0.89 \\
\hline Yes & 67 & 73 & 74 & 72 & \\
\hline No & 33 & 27 & 26 & 28 & \\
\hline Access to pasture (milking cows) & & & & & 0.70 \\
\hline Yes & 33 & 20 & 30 & 28 & \\
\hline No & 67 & 80 & 70 & 70 & \\
\hline Milking frequency (times per d) & & & & & 0.80 \\
\hline
\end{tabular}

high. A lower prevalence of lameness and hock and knee lesions was found on farms using only compost-bedded pack barns compared with those using only freestalls or the freestall farms that used a compost-bedded pack strategically for vulnerable cows. Interestingly, the lower prevalence of lameness in the compost-bedded pack farms did not come at the expense of either production or hygiene of the herd. However, despite our original prediction, in this study we found no benefit of providing a compost-bedded pack for vulnerable cows in conjunction with freestall use.

The mean prevalence of clinical lameness on confined dairies has been reported to exceed $25 \%$ by some (see United States and Canada, von Keyserlingk et al., 2012; China, Chapinal et al., 2014), whereas others report a lower prevalence (15\%, Canada, Westin et al., 2016; 14\%, United States, Foditsch et al., 2016; 9.6\%, United States, Adams et al., 2017). It is worrisome that the overall average across all farms in the current study was $42.5 \%$ for clinical lameness and $21.2 \%$ for severe lameness; both were considerably higher than the majority of studies completed in other regions, including grazing dairies in southern Brazil (Costa et al., 2013). As reported in other parts of the world (von Keyserlingk et al., 2012; Chapinal et al., 2014), the variation in the prevalence of lameness between farms was high within the same housing system, with some farms maintaining very low rates of lameness and hock and knee lesions. This highlights that the management practices of some producers are better able to mitigate lameness and hock and knee lesions. Several elements of dairy farms influence lameness prevalence on dairy farms, such as the dimensions of the stall, presence of a neck rail, the use of deep-bedded stalls, stall presence and maintenance, and access to pasture (Livesey et al., 2002; Fulwider et al., 2007; Chapinal et al., 2013). Future work should investigate how these factors influence the high prevalence of lameness found in this region. We found no differences among housing systems for management practices such as hoof or feed management, the provision of pasture or heat abatement strategies, the presence of overstocking, the type of bedding used within the freestalls, type of flooring in walkways, or available feed bunk and water trough space per cow.

Of the 3 types of housing systems visited in this study, the prevalence of lameness was lowest on the compost-bedded pack farms. Others have also shown that cows housed on compost-bedded packs had reduced prevalence of claw disorders (Burgstaller et al., 2016) and clinical lameness, but not severe lameness (Lobeck et al., 2011). The risk of developing white line disease and sole hemorrhages was also less for cows housed on compost-bedded packs (Livesey et al., 1998). In contrast, Eckelkamp et al. (2016a) reported no differences in the prevalence of lameness between freestall and compost-bedded packs.

Despite being lower than either the freestall or the blended freestall/compost farms, we still found a high prevalence of clinical (31.9\%) and severe (14.2\%) lameness on farms using compost-bedded packs; similar to Eckelkamp et al. (2016a) who reported 39.2 and 10.7\% clinical and severe lameness, respectively, in the United 
States. It is interesting to note that the majority of other studies report prevalence of clinical lameness on compost farms to be at most $12 \%$ [e.g., Black et al.
(2013): $11.9 \%$ clinical, $5.0 \%$ severe; Shane et al. (2010): 9.1\% clinical, 2.5\% severe; Lobeck et al. (2011): $4.4 \%$ clinical, $0.8 \%$ severe]. Future work should aim to disen-

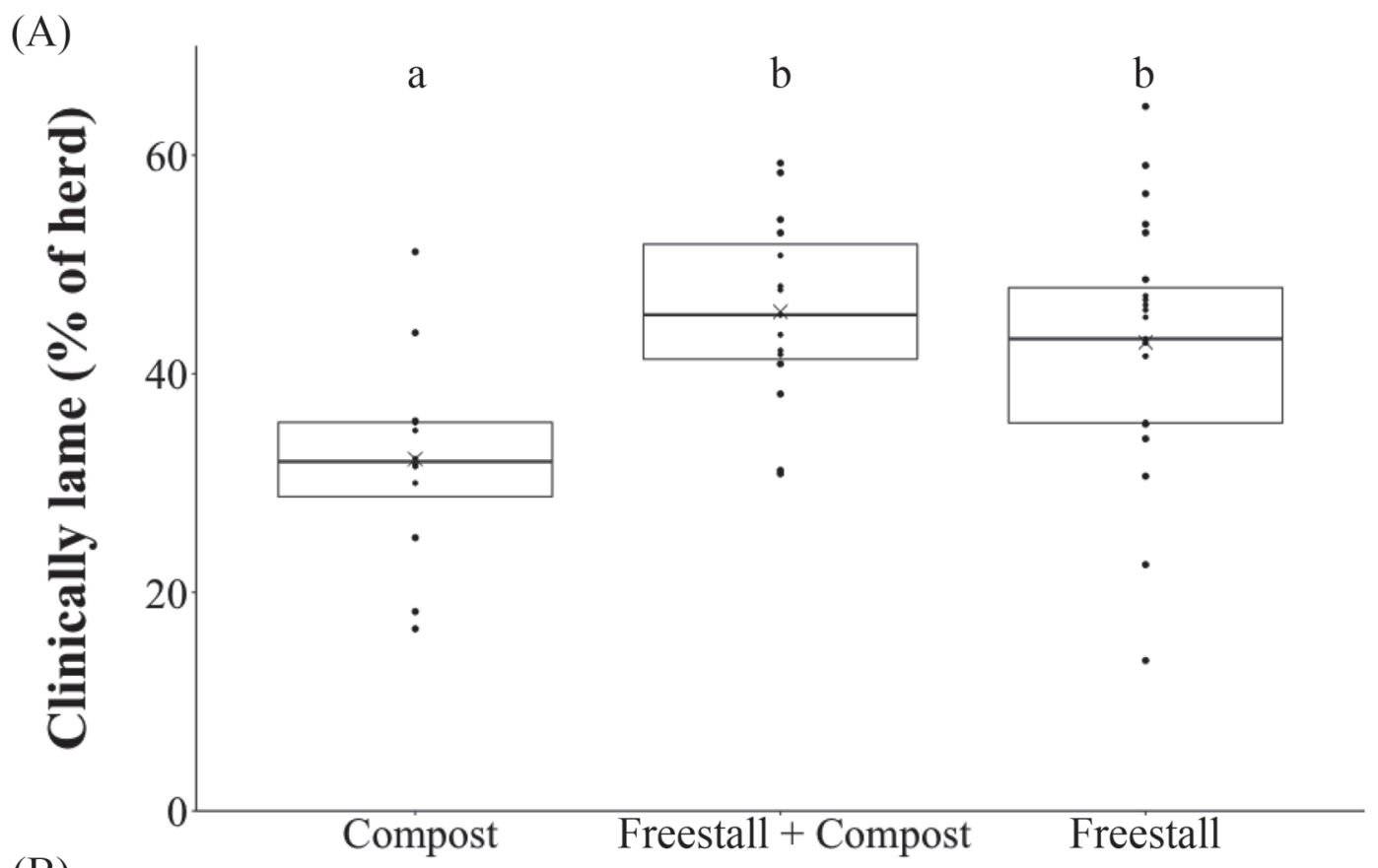

(B)

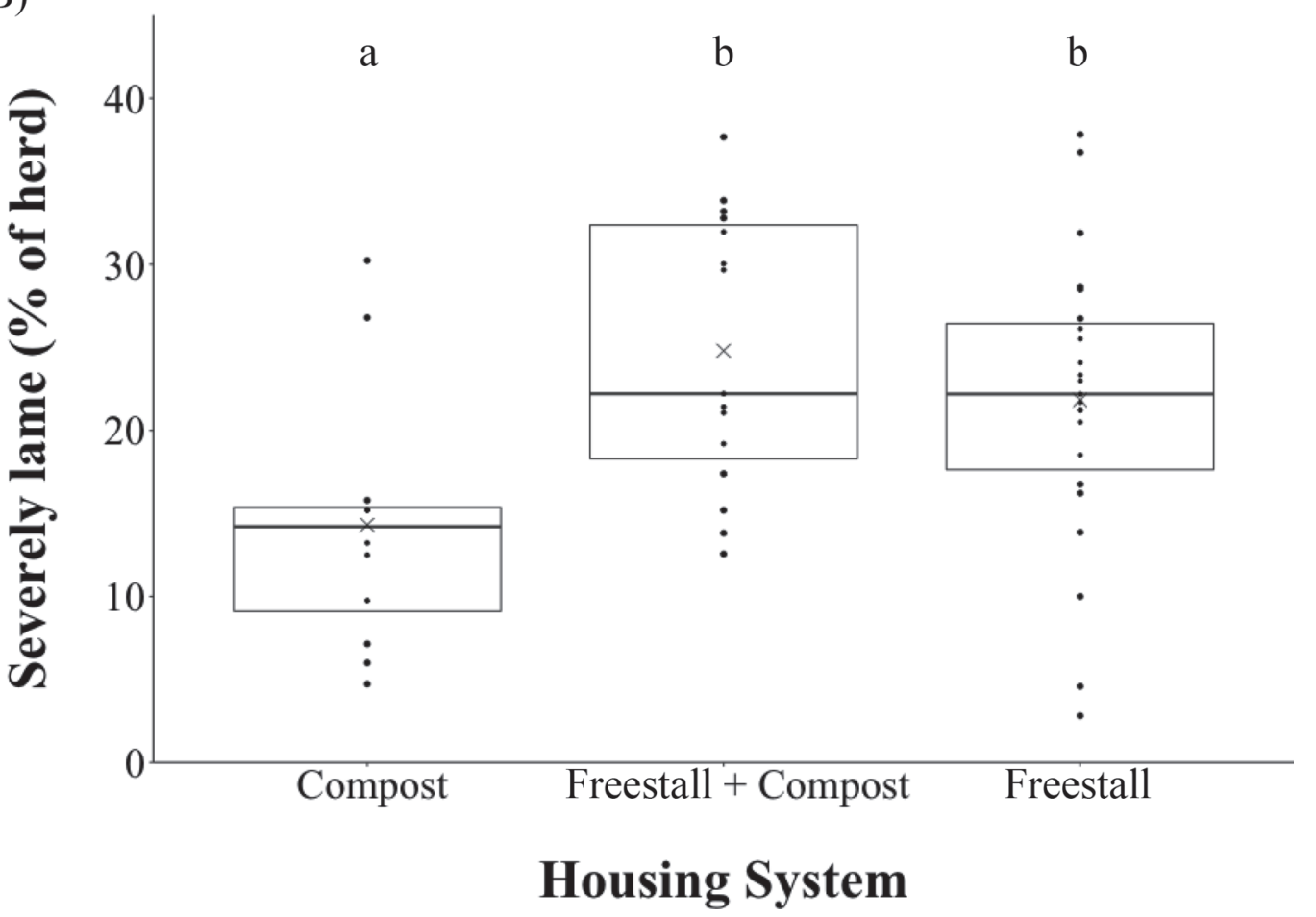

Figure 1. Boxplot of prevalence of $(\mathrm{A})$ clinical lameness (numerical rating system $\geq 3$ ) and (B) severe lameness (numerical rating system >4) of the entire herd on dairies utilizing compost-bedded packs, freestalls, and freestalls with a compost-bedded pack for vulnerable cows visited in Paraná, Brazil. Mean values are indicated by X and median by the solid black line, and the box indicates interquartile range (Q1-Q3). Individual farm prevalence values are represented by the black filled circles overlaying the boxplot. Letters (a, b) denote differences between housing systems $(P<0.05)$. 
tangle the risk factors for lameness associated with the use of compost-bedded packs compared with those for alternative housing systems.

Lameness or leg lesion prevalence was not different on freestall farms using a compost-bedded pack for vul- nerable cows compared with farms using only freestalls. The practice of moving lame cows to a comfortable surface such as pasture has been reported to aid in reducing the prevalence of lameness (Hernandez-Mendo et al., 2007). Farms that had compost-bedded pack barns

(A)

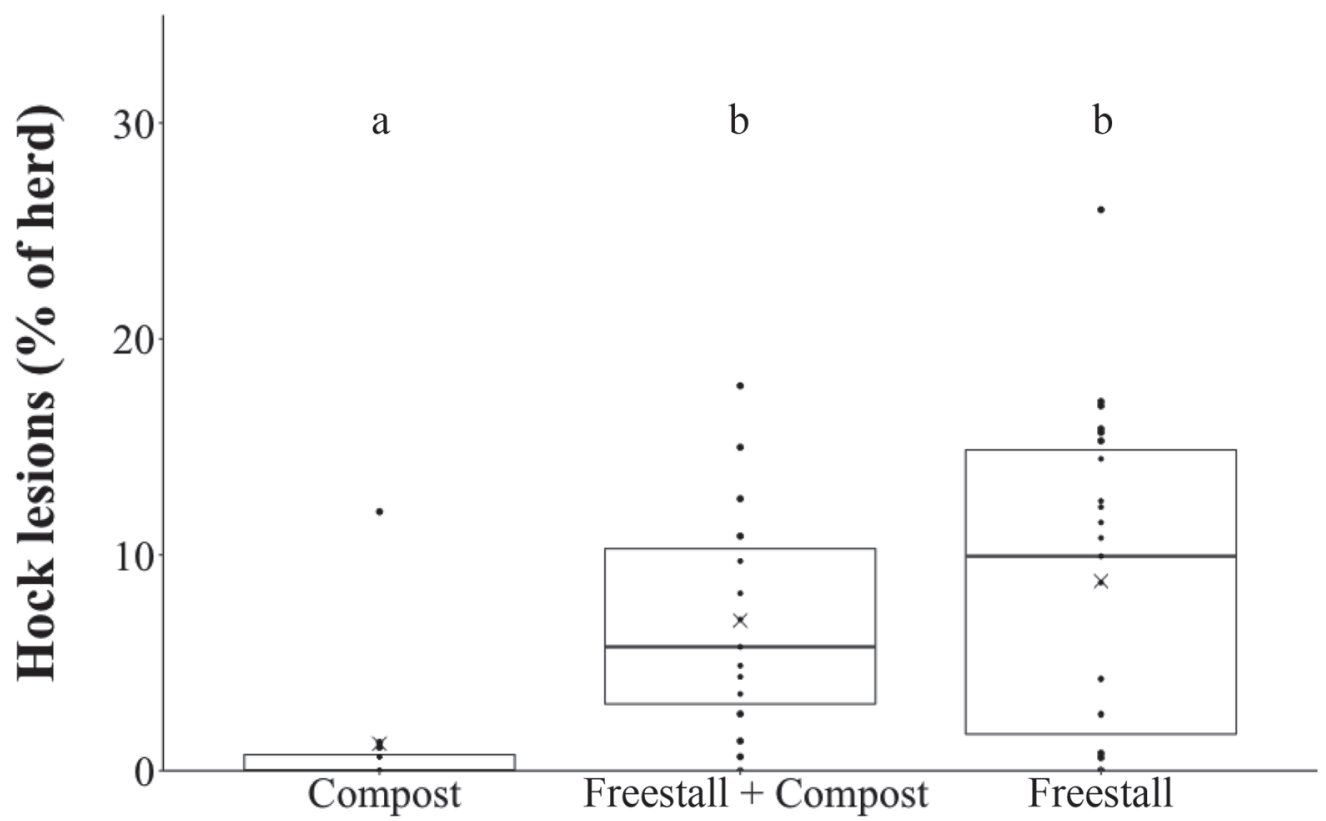

(B)

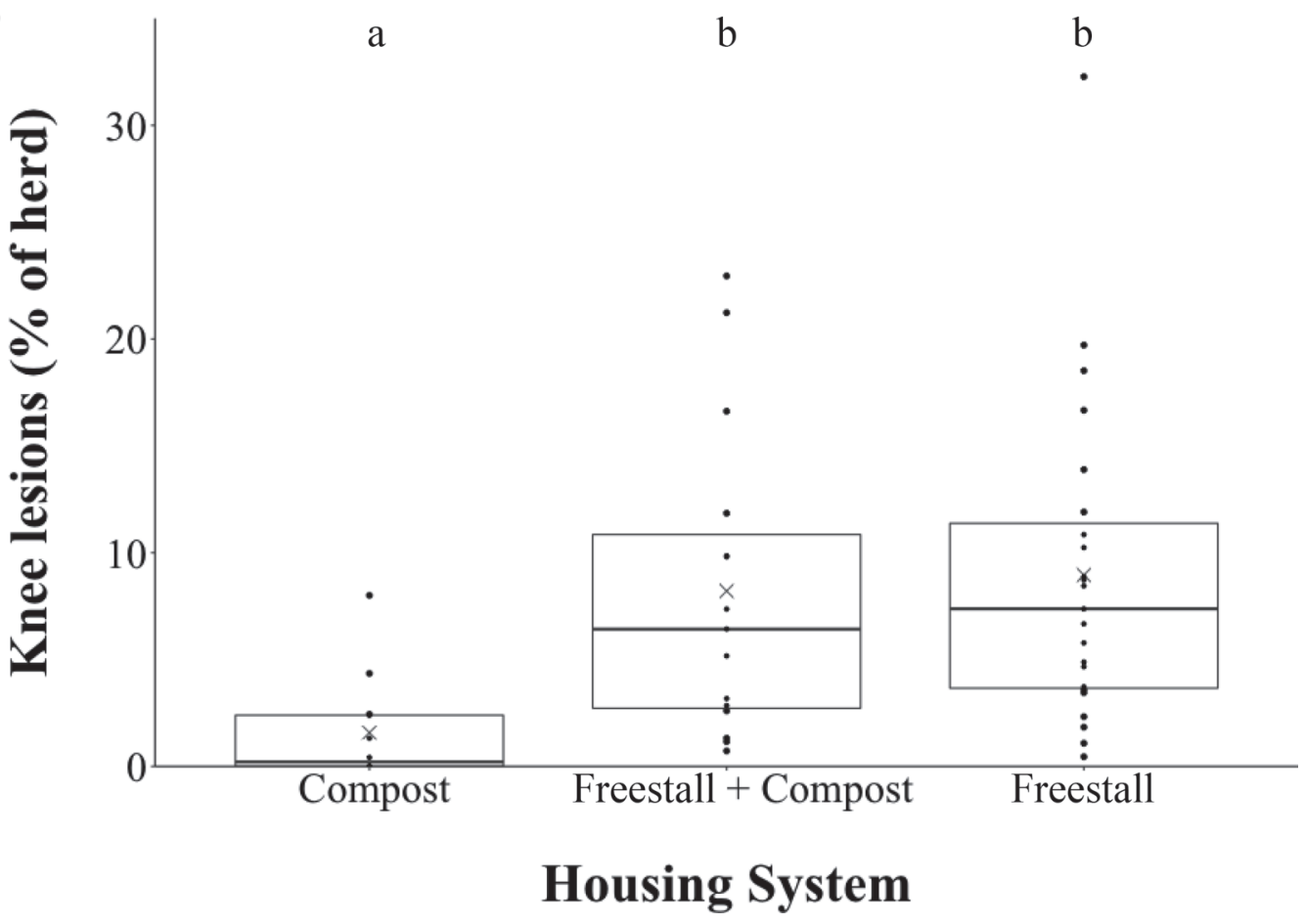

Figure 2. Boxplot of prevalence of (A) hock lesions and (B) knee lesions of the entire herd on dairies utilizing compost-bedded packs, freestalls, and freestalls with a compost-bedded pack for vulnerable cows visited in Paraná, Brazil. Mean values are indicated by X and median by the solid black line, and the box indicates interquartile range (Q1-Q3). Individual farm prevalence values are represented by the black filled circles overlaying the boxplot. Letters $(\mathrm{a}, \mathrm{b})$ denote differences between housing systems $(P<0.05)$. 
Table 4. Prevalence of cows with thin, obese, and ideal BCS, and cows with dirty legs, flanks, and udder on dairies utilizing compost-bedded packs, freestalls, and freestalls with compost-bedded packs for vulnerable cows visited in Paraná, Brazil ${ }^{1}$

\begin{tabular}{|c|c|c|c|c|c|}
\hline Variable & $\begin{array}{l}\text { Compost } \\
(\mathrm{n}=12)\end{array}$ & $\begin{array}{c}\text { Strategic use } \\
\text { of compost }(\mathrm{n}=15)\end{array}$ & $\begin{array}{l}\text { Freestall } \\
(\mathrm{n}=23)\end{array}$ & $\begin{array}{c}\text { Overall } \\
(\mathrm{n}=50)\end{array}$ & $P$-value \\
\hline \multicolumn{6}{|l|}{$\overline{\mathrm{BCS}^{2}}$} \\
\hline Ideal & $100(99.5-100)$ & $99.7(98.2-100)$ & $99.4(98.9-100)$ & $99.8(99.0-100)$ & 0.24 \\
\hline \multicolumn{6}{|l|}{ Hygiene $^{3}$} \\
\hline Udder & $0(0-9.4)$ & $2.1(1.1-12.3)$ & $2.1(0.6-7.5)$ & $1.66(0-9.3)$ & 0.42 \\
\hline
\end{tabular}

${ }^{1}$ Values are reported as median percentages (quartile $1-3$ ).

${ }^{2} \mathrm{BCS}$ was classified as thin $($ score $\leq 2.5)$, fat $($ score $\geq 4.5$ ), or ideal $($ score $>2$ and $<4.5$ ).

${ }^{3}$ Cows were considered dirty in a body region with a hygiene score $\geq 2$.

coupled with freestall barns have reportedly shown other benefits such as lower bulk talk SCC compared with farms using only compost-bedded packs, freestalls, or tiestalls, and other mixed housing systems (Eckelkamp et al., 2016a). Future research should investigate the benefits associated with the strategic use of compost bedded-packs for vulnerable cows, and in particular, an understanding of which types of conditions or diseases can be mitigated most effectively by using this system, and how long cows must be housed on the compostbedded pack to show benefits.

Hock and knee lesions were also found to be lowest in cows housed solely on compost-bedded packs compared with freestall and freestall farms using compost-bedded packs for vulnerable cows. However, the overall prevalence of leg lesions on the freestall farms was similar to other studies investigating freestall dairies (e.g., Cook et al., 2016; see review by Kester et al., 2014). Many environmental factors, such as deep bedding, access to pasture, nonslippery alleyways, and stall maintenance (Livesey et al., 2002; Barrientos et al., 2013; Burow et al., 2013; de Vries et al., 2015), decrease leg lesions on cows housed in freestalls. Softer and drier bedding has also been reported to decrease the risk of hock lesions (van Gastelen et al., 2011). Compost-bedded packs offer a softer bedding area for cows to lie down, provoking less friction on the lying surface compared with many stall bases used in freestalls (Lobeck et al., 2011). Primiparous cows housed in straw bedding have also been reported to develop fewer hock lesions when housed on a pack compared with cubicles (Livesey et al., 2002). Several studies have reported similar findings to that reported herein. For example, $1 \%$ of cows had swollen hocks in a US study (Barberg et al., 2007), whereas no hock or body lesions were reported for cows on compost-bedded packs in Israel (Klaas et al., 2010). Similarly, Lobeck et al. (2011) found $3.8 \%$ of cows to have moderate hock lesions and only $1 \%$ had severe hock lesions. When considering all types of leg lesions, Fulwider et al. (2007) and Lobeck et al. (2011) found a lower prevalence (score $\geq 2$ ) on compost-bedded packs than on cross-ventilated or naturally ventilated sand-bedded freestalls. In contrast, Eckelkamp et al. (2016a) did not find any difference in leg lesions between compost-bedded packs and sand-bedded freestall barns. Interestingly, we found similar hock and knee injury prevalence on the farms that used a combination of compost-bedded packs and freestalls and farms using only freestalls. Once lesions have developed they are difficult to cure (Barberg et al., 2007; see review by Kester et al., 2014), so some cows on the combination of freestall and compost-bedded pack farms may have developed lesions when housed in the freestall portion of the farm, which may have failed to heal despite being housed on the compost. Unfortunately, we do not know the history of lameness or lesions on these farms before their use of compost-bedded packs, which could explain the lack of difference in injury prevalence between these farms. Future work should investigate if housing cows on compost-bedded packs can mitigate hock and knee lesions, and if so, which factors are associated with this improvement and how long is required for lesions to heal once cows are moved onto the compost-bedded packs.

As a cross-sectional study, we cannot infer causal relationships among the housing systems and the prevalence of lesions or lameness. Many factors influence lameness and lesion prevalence in dairy cattle such as the type of bedding, stall dimensions, genetics of the animals, and many others that could not be collected in this study. This study was based on a convenience sample of farms in the region and thus is not representative of the whole industry within Paraná State (Brazil). 


\section{CONCLUSIONS}

Overall, the prevalence of lameness on dairy farms was high in the Paraná region of Brazil. Farms that used a compost-bedded pack for their lactating dairy cows had the lowest prevalence of lameness and leg injuries compared with both freestall farms and those using a combination of freestall and a compost-bedded pack. Lameness and leg injuries continue to be one of the most serious welfare issues facing the dairy industry.

\section{ACKNOWLEDGMENTS}

We thank the farmers, local extension agents, and veterinarians that participated in this study, as well as Paulo Henrique Manske Doering, Vanessa Groenwold, Luis Andrés Gonzalez, Gabriela Marquete, and Angélica Roslindo for their help with data collection. We also thank the Castrolanda Cooperativa Agroindustrial (Castro, PR, Brazil), Capal Cooperativa Agroindustrial (Arapoti, PR, Brazil), and Cooperativa Agropecuária Witmarsum (Witmarsun, PR, Brazil), specially Hugo Richard Dick, Rodrigo Navarro, Junio Fabiano dos Santos, and Gunther Schartner for their help with identification of farms and sharing their knowledge about the milk production systems in the region. This research was funded by the Science Without Borders Program (CNPq-National Council for Scientific and Technological Development, Brazil, Grant No. 400850/2013-3), which also provided funds to M. A. G. von Keyserlingk for visits to Brazil that enabled this outstanding collaboration. Maria J. Hötzel received support from CNPq (Grant No. 311509/2015-0). J. H. C. Costa was supported by a postdoctoral fellowship from CAPES (Ministry of Education, Brazil) and University of British Columbia Animal Welfare (Vancouver, BC, Canada) program throughout the development of the project. T. A. Burnett was supported by a scholarship from Mitacs-Canada (Ottawa, ON, Canada).

\section{REFERENCES}

Adams, A. E., J. E. Lombard, C. P. Fossler, I. N. Román-Muñiz, and C. A. Kopral. 2017. Associations between housing and management practices and the prevalence of lameness, hock lesions, and thin cows on US dairy operations. J. Dairy Sci. 100:2119-2136. https://doi.org/10.3168/jds.2016-11517.

Andreasen, S. N., and B. Forkman. 2012. The welfare of dairy cows is improved in relation to cleanliness and integument alterations on the hocks and lameness when sand is used as stall surface. J. Dairy Sci. 95:4961-4967.

Bach, A., M. Dinarés, M. Devant, and X. Carré. 2007. Associations between lameness and production, feeding and milking attendance of Holstein cows milked with an automatic milking system. J. Dairy Res. 74:40-46. https://doi.org/10.1017/S0022029906002184.

Barberg, A. E., M. I. Endres, J. A. Salfer, and J. K. Reneau. 2007. Performance and welfare of dairy cows in an alternative housing system in Minnesota. J. Dairy Sci. 90:1575-1583.
Barrientos, A. K., N. Chapinal, D. M. Weary, E. Galo, and M. A. G. Von Keyserlingk. 2013. Herd-level risk factors for hock injuries in freestall-housed dairy cows in the northeastern United States and California. J. Dairy Sci. 96:3758-3765.

Bicalho, R. C., F. Vokey, H. N. Erb, and C. L. Guard. 2007. Visual locomotion scoring in the first seventy days in milk: impact on pregnancy and survival. J. Dairy Sci. 90:4586-4591. https://doi .org/10.3168/jds.2007-0297.

Black, R. A., J. L. Taraba, G. B. Day, F. A. Damasceno, and J. M. Bewley. 2013. Compost bedded pack dairy barn management, performance, and producer satisfaction. J. Dairy Sci. 96:8060-8074.

Bouffard, V., A. M. de Passillé, J. Rushen, E. Vasseur, C. G. R. Nash, D. B. Haley, and D. Pellerin. 2017. Effect of following recommendations for tiestall configuration on neck and leg lesions, lameness, cleanliness, and lying time in dairy cows. J. Dairy Sci. 100:29352943.

Burgstaller, J., J. Raith, S. Kuchling, V. Mandl, A. Hund, and J. Kofler. 2016. Claw health and prevalence of lameness in cows from compost bedded and cubicle freestall dairy barns in Austria. Vet. J. 216:81-86.

Burow, E., P. T. Thomsen, T. Rousing, and J. T. Sørensen. 2013. Daily grazing time as a risk factor for alterations at the hock joint integument in dairy cows. Animal 7:160-166.

Ceballos, A., D. Sanderson, J. Rushen, and D. M. Weary. 2004. Improving stall design: Use of 3-D kinematics to measure space use by dairy cows when lying down. J. Dairy Sci. 87:2042-2050.

Chapinal, N., A. K. Barrientos, M. A. G. von Keyserlingk, E. Galo, and D. M. Weary. 2013. Herd-level risk factors for lameness in freestall farms in the northeastern United States and California. J. Dairy Sci. 96:318-328.

Chapinal, N., Y. Liang, D. M. Weary, Y. Wang, and M. A. G. von Keyserlingk. 2014. Risk factors for lameness and hock injuries in Holstein herds in China. J. Dairy Sci. 97:4309-4316.

Chebel, R. C., P. R. B. Silva, M. I. Endres, M. A. Ballou, and K. L. Luchterhand. 2016. Social stressors and their effects on immunity and health of periparturient dairy cows. J. Dairy Sci. 99:32173228

Cook, N. B., J. P. Hess, M. R. Foy, T. B. Bennett, and R. L. Brotzman. 2016. Management characteristics, lameness, and body injuries of dairy cattle housed in high-performance dairy herds in Wisconsin. J. Dairy Sci. 99:5879-5891.

Cook, N. B., and K. V. Nordlund. 2004. Behavioral needs of the transition cow and considerations for special needs facility design. Vet. Clin. N. Am. Food Anim. Pract. 20:495-520.

Cook, N. B., and K. V. Nordlund. 2009. The influence of the environment on dairy cow behavior, claw health and herd lameness dynamics. Vet. J. 179:360-369.

Costa, J. H. C., M. J. Hötzel, C. Longo, and L. F. Balcão. 2013. A survey of management practices that influence production and welfare of dairy cattle on family farms in southern Brazil. J. Dairy Sci. 96:307-317. https://doi.org/10.3168/jds.2012-5906.

DFC-NFACC. 2009. Dairy Farmers of Canada and National Farm Animal Care Council's Code of practice for the care and handling of dairy cattle. Accessed Oct. 12, 2017. http://www.nfacc.ca/pdfs/ codes/Dairy\%20Code\%20of\%20Practice.pdf.

de Vries, M., E. A. M. Bokkers, C. G. Van Reenen, B. Engel, G. Van Schaik, T. Dijkstra, and I. J. M. De Boer. 2015. Housing and management factors associated with indicators of dairy cattle welfare. Prev. Vet. Med. 118:80-92.

Eckelkamp, E. A., J. L. Taraba, K. A. Akers, R. J. Harmon, and J. M. Bewley. 2016a. Sand bedded freestall and compost bedded pack effects on cow hygiene, locomotion, and mastitis indicators. Livest. Sci. 190:48-57.

Eckelkamp, E. A., J. L. Taraba, K. A. Akers, R. J. Harmon, and J. M. Bewley. 2016b. Understanding compost bedded pack barns: Interactions among environmental factors, bedding characteristics, and udder health. Livest. Sci. 190:35-42.

Edmonson, A. J., I. J. Lean, L. D. Weaver, T. Farver, and G. Webster. 1989. A body condition scoring chart for Holstein dairy cows. J. Dairy Sci. 72:68-78. 
Endres, M. I., and A. E. Barberg. 2007. Behavior of dairy cows in an alternative bedded-pack housing system. J. Dairy Sci. 90:41924200.

Fjeldaas, T., Å. M. Sogstad, and O. Østerås. 2011. Locomotion and claw disorders in Norwegian dairy cows housed in freestalls with slatted concrete, solid concrete, or solid rubber flooring in the alleys. J. Dairy Sci. 94:1243-1255.

Flower, F. C., and D. M. Weary. 2006. Effect of hoof pathologies on subjective assessments of dairy cow gait. J. Dairy Sci. 89:139-146.

Foditsch, C., G. Oikonomou, V. S. Machado, M. L. Bicalho, E. K. Ganda, S. F. Lima, R. Rossi, B. L. Ribeiro, A. Kussler, and R. C. Bicalho. 2016. Lameness prevalence and risk factors in large dairy farms in upstate New York. Model development for the prediction of claw horn disruption lesions. PLoS One 11:e0146718 https://doi .org/10.1371/journal.pone.0146718.

Fulwider, W. K., T. Grandin, D. J. Garrick, T. E. Engle, W. D. Lamm, N. L. Dalsted, and B. E. Rollin. 2007. Influence of free-stall base on tarsal joint lesions and hygiene in dairy cows. J. Dairy Sci. 90:3559-3566.

Hernandez-Mendo, O., M. A. G. von Keyserlingk, D. M. Veira, and D. M. Weary. 2007. Effects of pasture on lameness in dairy cows. J. Dairy Sci. 90:1209-1214.

IPARDES. 2009. Sumário executive do Instituto Paranaense de Desenvolvimento Econômico e Social (IPARDES). Curitiba, 2009. Accessed Oct. 2017. http://www.ipardes.gov.br/biblioteca/docs/ sumario_executivo_atividade_leiteira_parana.pdf.

Janni, K. A., M. I. Endres, J. K. Reneau, and W. W. Schoper. 2007. Compost dairy barn layout and management recommendations. Appl. Eng. Agric. 23:97-102.

Kester, E., M. Holzhauer, and K. Frankena. 2014. A descriptive review of the prevalence and risk factors of hock lesions in dairy cows. Vet. J. 202:222-228.

Klaas, I. C., B. Bjerg, S. Friedmann, and D. Bar. 2010. Cultivated barns for dairy cows-an option to promote cattle welfare and environmental protection in Denmark? Dansk Vettidsskr. 93:20-29.

Klaas, I. C., and B. S. Bjerg. 2011. Compost barns-An alternative housing system for dairy cows? Anim. Sci. Rev. 6:145.

Leach, K. A., D. A. Tisdall, N. J. Bell, D. C. J. Main, and L. E. Green. 2012. The effects of early treatment for hindlimb lameness in dairy cows on four commercial UK farms. Vet. J. 193:626-632. https:// doi.org/10.1016/j.tvjl.2012.06.043.

Livesey, C. T., T. Harrington, A. M. Johnston, S. A. May, and J. A. Metcalf. 1998. The effect of diet and housing on the development of sole haemorrhages, white line haemorrhages and heel erosions in Holstein heifers. Anim. Sci. 67:9-16.

Livesey, C. T., C. Marsh, J. A. Metcalf, and R. A. Laven. 2002. Hock injuries in cattle kept in straw yards or cubicles with rubber mats or mattresses. Vet. Rec. 150:677-679.

Lobeck, K. M., M. I. Endres, E. M. Shane, S. M. Godden, and J. Fetrow. 2011. Animal welfare in cross-ventilated, compost-bedded pack, and naturally ventilated dairy barns in the upper Midwest. J. Dairy Sci. 94:5469-5479.

Lombard, J. E., C. B. Tucker, M. A. G. von Keyserlingk, C. A. Kopral, and D. M. Weary. 2010. Associations between cow hygiene, hock injuries, and free stall usage on US dairy farms. J. Dairy Sci 93:4668-4676.

Metz, J. H. M., T. Dijkstra, P. Franken, and K. Frankena. 2015. Development and application of a protocol to evaluate herd welfare in Dutch dairy farms. Livest. Sci. 180:183-193.

Norring, M., E. Manninen, A.M. de Passillé, J. Rushen, L. Munksgaard, and H. Saloniemi. 2008. Effects of sand and straw bedding on the lying behavior, cleanliness, and hoof and hock injuries of dairy cows. J. Dairy Sci. 91:570-576.

O'Callaghan, K. A., P. J. Cripps, D. Y. Downham, and R. D. Murray. 2003. Subjective and objective assessment of pain and discomfort due to lameness in dairy cattle. Anim. Welf. 12:605-610.

Palmer, M. A., and N. E. O'Connell. 2015. Digital dermatitis in dairy cows: A review of risk factors and potential sources of betweenanimal variation in susceptibility. Animals (Basel) 5:512-535.

Potterton, S. L., N. J. Bell, H. R. Whay, E. A. Berry, O. C. D. Atkinson, R. S. Dean, D. C. J. Main, and J. N. Huxley. 2012. A descriptive review of the peer and non-peer reviewed literature on the treatment and prevention of foot lameness in cattle published between 2000 and 2011. Vet. J. 193:612-616. https://doi.org/10 .1016/j.tvjl.2012.06.040.

Roche, J. R., N. C. Friggens, J. K. Kay, M. W. Fisher, K. J. Stafford, and D. P. Berry. 2009. Invited review: Body condition score and its association with dairy cow productivity, health, and welfare. J. Dairy Sci. 92:5769-5801.

Rushen, J., A. M. de Passillé, M. A. G. von Keyserlingk, and D. M. Weary. 2008. The Welfare of Cattle. Springer, Dordrecht, the Netherlands.

Shane, E. M., M. I. Endres, and K. A. Janni. 2010. Alternative bedding materials for compost bedded pack barns in Minnesota: A descriptive study. Appl. Eng. Agric. 26:465-473.

Solano, L., H. W. Barkema, E. A. Pajor, S. Mason, S. J. LeBlanc, J. C. Zaffino Heyerhoff, C. G. R. Nash, D. B. Haley, E. Vasseur, D Pellerin, J. Rushen, A. M. de Passillé, and K. Orsel. 2015. Prevalence of lameness and associated risk factors in Canadian HolsteinFriesian cows housed in freestall barns. J. Dairy Sci. 98:6978-6991.

van Gastelen, S., B. Westerlaan, D. J. Houwers, and F. J. C. M. van Eerdenburg. 2011. A study on cow comfort and risk for lameness and mastitis in relation to different types of bedding materials. J. Dairy Sci. 94:4878-4888.

von Keyserlingk, M. A. G., A. Barrientos, K. Ito, E. Galo, and D. M. Weary. 2012. Benchmarking cow comfort on North American freestall dairies: Lameness, leg injuries, lying time, facility design, and management for high-producing Holstein dairy cows. J. Dairy Sci. 95:7399-7408. https://doi.org/10.3168/jds.2012-5807.

Westin, R., A. Vaughan, A. M. de Passillé, T. J. DeVries, E. A. Pajor, D. Pellerin, J. M. Siegford, A. Witaifi, E. Vasseur, and J. Rushen. 2016. Cow- and farm-level risk factors for lameness on dairy farms with automated milking systems. J. Dairy Sci. 99:3732-3743. https://doi.org/10.3168/jds.2015-10414.

Whay, H. R., D. C. J. Main, L. E. Green, and A. J. F. Webster. 2003 Assessment of the welfare of dairy cattle using animal-based measurements: Direct observations and investigation of farm records. Vet. Rec. 153:197-202. 